\title{
Social Media Impact on Social Life of Public Servant in Mari Mansa District, Dawuro Zone, Southern Region, Ethiopia
}

\author{
Lisanu Damene Daracho \\ Jimma University P.O.Box 307 Jimma Ethiopia
}

\begin{abstract}
Social media use in public servants of the district has been highly increased in last five years. This study examined the social media impact on social life of public servant in Mari Mansa District Dawuro Zone Southern Region Ethiopia. Simple random sampling technique was conducted from June 2019 to May 2020 in Mari Mansa district. 142 public servants for the study used which was used as sample size questionnaire was used to elicit information from respondents. The semi structured questionnaire used for this study was purposely designed to suit the study. The result was analyzed in terms of SPSS 20 and descriptive statistics followed by inferential statistics. Facebook, Messenger, Imo, Twitter, Gmail, Telegram, Instagram and TikTok are social media used by district public servants. Social media has positive and negative effects on office job performance, idea share, create new and improve old and customer satisfaction. To send and receive messages to friends, family and relatives, as fashion and globalization, to send and receive reports, to share field visit and observation, to visit different media are the main purposes of public servant use social media. There are many challenges in using social those caused by economical, social and technological.
\end{abstract}

Keywords: Challenges, Impacts, Mari Mansa, Opportunity, Social Media, Time Spent

DOI: $10.7176 / \mathrm{NMMC} / 93-01$

Publication date:September $30^{\text {th }} 2020$

\section{Introduction}

\subsection{Background of the study}

Communication has developed since ages as civilization and development goes hand in hand in recent time. In $21^{\text {st }}$ century the communication is very faster, best and efficient the credit goes largely to technology. Internet has highly changed the human experience of communication than others (Lev-on, 2017). Socialization is an important aspect of this developing technology. All internet users indicate one of their primary purposes of using internet for going online is for communication with other peoples. Communication used to the interaction of people using various social media platforms with the absence of geographical and time barriers for different purposes (Mesfin et al., 2017).

The revolution of internet is changed the information world with regard to sharing speed, storage and retrieval of information in whatever form regardless of the person's location. Through the internet a number of web technologies emerged and one technology that is making waves with regard to information sharing and communication are the social media networks. The evolution of social media has cut across all facets of society with its positive and negative impacts to those societies. Social media has transformed and impacted on communication, learning, working, research and education. The vast variety of online tools which are available for communication, idea sharing and social networking sites have become the most modern and attractive tools for connecting people throughout the world (Mergel, 2013).

The presence and activity on social media is no longer a question of choice for most governments as those new platforms empower individuals and non-traditional interest groups in different purposes. In social media politicians were first to react to these changes by using platforms such as Twitter, Facebook, Telegram, Twitter and blogs to rally support. Public institutions are slowly catching up and increasingly experiment with social media in last five years (Mickoleit, 2014).

The purpose and returns of social media use by public institutions are not as clear as they are for political personalities. This leads to uncertainty and risks among government institutions about how to best leverage social media and about the implications for strategic objectives and daily operations. Now a day social media drive innovation in public service delivery and government operations. They amplify some of the "democratisation" effects of the Internet on public information and services; and they provide opportunities to deliver on expectations that are not met by traditional online government services (Ahn, 2010).

The use of social media is increasingly very fast and becoming popular among the youths, a public servant, shopkeepers and higher education student in worldwide due to their interactive features (Lev-on, 2017). Public offices slowly but increasingly adopt social technologies to better serve their mission. Now a day people use social media for different purposes in the world. Social media constitute websites that are designed to help users to share information, exchange ideas and pears, feeling, different messages and participate in content modification online. These involve the platforms Facebook, Messenger, TikTok, YouTube, Twitter, Instagram, Telegram, Yahoo, Telegram and other similar interactive websites for similar purposes. These are widely in use among public 
services and students in different levels of education (Dhir and Tsai 2017).

According to (Asemah and Edegoh, 2012), social network is a social structure made up of individuals or organization called strong mortise which are tied by one or more specific types of interdependency such as friendship, office members, family, similar job runners, kinship, common interest, financial exchange, sexual relationship or relationships of belief, knowledge or prestige. Social network can map of specified ties, such as friendship, between nodes being studied and worked. The nodes, to which an individual is thus connected, are the social contacts of that individual; the network can also be used to measure social capital the value that an individual gets from the social network. These networking site are used by most people to interact with old and new friends. The expansion in technology has also affected software, thus leading to chatting sites known by the name 'social media', with social networking sites, people can send and receive message almost immediately.

Academic and job excellence or achievement plays an important role in an individual placement, be it in the academic institutions or job placement. Due to this, many people are concerned with the ways they can enhance their academic and job achievement of goals. The emphasis on academic and job excellence which is also prevalent worldwide has encouraged many studies about the conditions promoting it. The role of job achievement is one of the predictors of one's life success. Job performance, which is measured by the customer and his/her satisfaction, is one of the major goals of an individual and organization (Mesch, 2009).

The excessive use of social media has counter effect on the public servants pursuits by diverting their attention from job oriented activities to recreational oriented activities. Emotionally, the extensive use of social media can reduce peer interactions and may lead users to feel loneliness overtime. The personal risks that frequently happen to users on social media involve uploading unintended information in certain contexts, fake news, false information of organization, chasm users on false information without evidence, uploading negative information about oneself and the others; hacking others' accounts and being hacked; and using information for retaliation purposes, privacy problem, safety, and psychological well-being of user (Błachnio et al., 2016).

Job is very essential part of an individual's life for every person. Today public servant shows very much interest for using social networks but unfortunately social networks affect public and individual job negatively. In Ethiopia most public servant does not take their food on time and do not sleep on time which causes a very non serious attitude with job. Social media user public servant in Mari Mansa district use social media to chatting, commenting, sharing reports to kebeles, zones and regions, updating status, show their feeling, indicate their organization and district performance, sharing unrecommendable activity to others, to fake news, to indicate field work and sharing of information for their users.

Social media is open for anyone who has a valid e-mail address, the researcher believes that social media has significantly affected the way people are communicating and interacting with each other (Kietzmann, 2012). Social media has extra features other than sending receiving messages; the website includes members' pictures, sharing fake news, sharing organization performances, fashion expression, personal information, interests and group members. Social media users can choose their personal levels of security to prevent strangers from accessing their personal information. The platform enables and initiates anyone, anywhere, to build up complete applications that members can choose widely to use. Applications range from photo sharing to graffiti walls and everything in between.

There is no more studies have not been conducted so far on the impacts of social media on the public servant job achievement in the districts and Dawuro zone. Hence, findings from this study provide a starting point for public service authorities and all concerned groups to identify the effect of social media on job achievement of public servants in different office and take appropriate measures. Moreover, this study would serve as baseline information for future intervention program on effect of social media on public servant job achievement. Last but not least it will be helpful for government office program planners to consider effect of social media on public servant job achievement in their priority customer satisfaction issues. Therefore, this study was conducted to identify the impact of social media on public servant job achievement of Mari Mansa district.

\subsection{Objectives of the study}

The overall objective is social media impact on social life of public servant in Mari Mansa District Dawuro Zone Southern Region Ethiopia with specific objectives.

1. To examine the relationship between times spend on social media and office job performance of public servant.

2. To identify the main purposes why public servants of the district use social media.

3. To identify challenges and opportunities of social media

\section{Methodology}

\subsection{Study area}

Mari Mansa is one of the 10 districts and one town administration in the Dawuro zone. Mari Mans district is found in Dawuro zone of southern region and is located to the southwest of Ethiopia. The district extends from $6^{0} 54^{\prime}$ $00^{\prime \prime}$ to $7^{0} 00^{\prime} 00^{\prime \prime}$ North and $37^{\circ} 06^{\prime} 00^{\prime \prime}$ up to $37^{\circ} 00^{\prime} 00^{\prime \prime}$ East. 


\subsection{Types, sources and method of data collection}

\subsubsection{Methods of participant identification}

The participants of the study were selected from 26 government office namely office of (Police, Administration, prosperity organization, Finance and economic development, Women children and youth, Agriculture and natural resource development, Forest and environmental development, Coffee tea and species, Water and minerals, Animal and Fisheries, Urban housing and construction, Culture tourism and sport, Labor and social security, Peace and security, Administration council, Education, Health, Courts, Public Human Resource Management, Business enterprises and industry development, Milsha, Road and Transport, Municipal, Cooperative, Revenue and Trade) from Mari Mansa district which were assumed to have considerable number of social media users.

\subsubsection{Types and source of data}

Both qualitative and quantitative types of data were collected from primary and secondary sources. Primary data: Were data collected from selected public servant in 26 office of the district. Secondary data: Were data collected from published and unpublished reports, bulletins and websites.

\subsubsection{Methods of data collection}

Data for this study were personally collected by the researcher through a combination of both in depth interview and questionnaire methods of data collection. The research questionnaire was conducted in English language and translated to Amharic through the research instrument purposely designed for the study. The questionnaire used for this study was purposely designed to suit the study. The data collected for this study collected by researcher via different data collection instruments. The semi structured questionnaire is prepared in questionnaire and checklist for focus group discussion. Focus group discussion was to clear some difficult question.

\subsubsection{Sampling procedure and sample size}

A simple random sampling technique was used to select sample public servants. Each member of the defined population has an equal opportunity to be part of the study. The randomly selected sample answered a survey written questionnaire. The total number of public servant participated in the study are 142 public servants from 519,412 total number and social media user public servants respectively. The number of samples varied from sector to sector according the total numbers public servants and social media user public servants in office.

\subsubsection{Method of data analysis}

The data collected were processed and analyzed with the new statistical package for social science (SPSS 20) and descriptive statistics, such as frequency distribution tables, percentage distribution and charts. This level of analysis was used to provide a general descriptive of the socio-demographic characteristics in line with the objectives.

\section{Results and Discussions}

\subsection{Demographic characteristics and participants selection from offices}

The sex of public servant, $101(71.13 \%)$ were male and $41(28.87 \%)$ were females. From sampled public servants participated in this study $42 \%$ were married, 55.5 were single and 2.5 were divorced. The average age of the respondents were found to be 34.32 years old. However the level of education of sampled public servants indicated by the using the study results, about $2 \%$ of the respondents are illiterate, $2.75 \%$ and $3 \%$ attended primary school and secondary school respectively where as $29.5 \%$ are diploma holders, 58.75 were first degree graduates and $4 \%$ were second degree graduates. Table 1 below indicates participants' selection. Table 1: The number of social media user public servant from different offices

\begin{tabular}{|c|c|c|c|c|}
\hline No & Name of office & $\begin{array}{l}\text { Total public } \\
\text { servant }\end{array}$ & $\begin{array}{l}\text { Social media user } \\
\text { public servant }\end{array}$ & Sampled \\
\hline 1 & Administration & 13 & 7 & 3 \\
\hline 2 & Police & 33 & 23 & 8 \\
\hline 3 & Prosperity organization & 6 & 6 & 2 \\
\hline 4 & Finance and economic development & 23 & 20 & 7 \\
\hline 5 & Women children and youth & 18 & 15 & 5 \\
\hline 6 & Agriculture and natural resource & 31 & 32 & 11 \\
\hline 7 & Forest and environmental development & 19 & 16 & 5 \\
\hline 8 & Coffee tea and species & 12 & 9 & 3 \\
\hline 9 & Water and minerals & 15 & 15 & 5 \\
\hline 10 & Animal and Fisheries & 22 & 17 & 8 \\
\hline 11 & Urban housing and construction & 15 & 13 & 4 \\
\hline 12 & Culture tourism and sport & 17 & 11 & 4 \\
\hline 13 & Labor and social security & 20 & 14 & 5 \\
\hline 14 & Peace and security & 16 & 10 & 3 \\
\hline 15 & Administration council & 13 & 13 & 4 \\
\hline 16 & Education & 32 & 24 & 8 \\
\hline
\end{tabular}




\begin{tabular}{lllll}
\hline No & Name of office & $\begin{array}{l}\text { Total public } \\
\text { servant }\end{array}$ & $\begin{array}{c}\text { Social media user } \\
\text { public servant }\end{array}$ & Sampled \\
\hline 17 & Health & 22 & 17 & 7 \\
18 & Courts & 24 & 20 & 7 \\
19 & Public Human Resource Management & 17 & 13 & 4 \\
20 & Enterprises and industry development & 27 & 25 & 3 \\
21 & Milsha & 13 & 8 & 6 \\
22 & Road and Transport & 22 & 17 & 4 \\
23 & Municipal & 18 & 12 & 3 \\
24 & Cooperative & 16 & 10 & 10 \\
25 & Revenue & 29 & 29 & 5 \\
26 & Trade & 26 & 16 & 142 \\
\hline
\end{tabular}

Source: Own survey result 2019/2020

\subsection{Social media use of public servant in the district}

\subsubsection{Types of social media used district public servant}

Public servants of Mari Mansa district use different types of social media. The most known social media used by public servants are Facebook, Messenger, Imo, Twitter, Gmail, Telegram, Instagram and TikTok. But most of the users use Facebook followed by Telegram and Messenger. In figure 1 below indicate above 43.66\% public servants were use Facebook and followed by $7.04 \%$ Telegram and $6.33 \%$ messenger. This number indicates Facebook use by public servant take lion share of social media in the district.

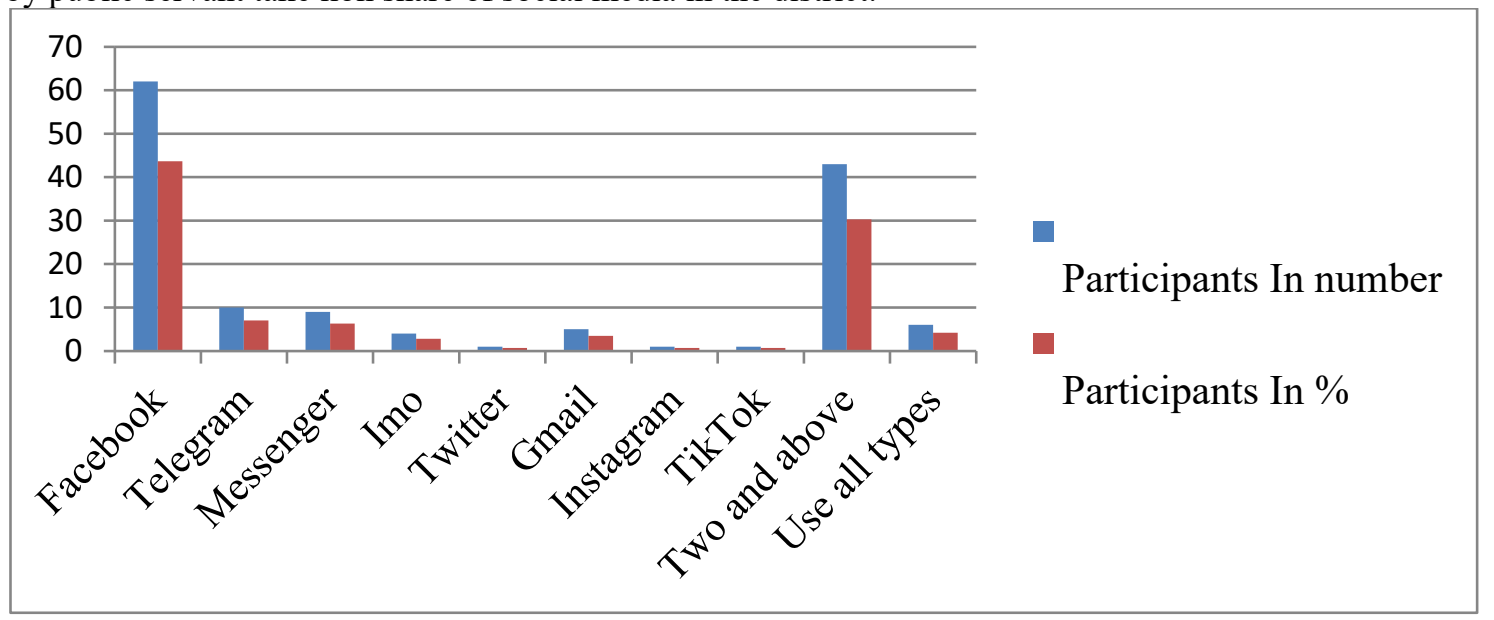

Figure 1: Types of social media used by public servants in district

Source: Own survey result (2019/2020).

\subsubsection{The relationship between times spend on social media and office job performance}

The study result indicated that public servant social media use is increasing from to time in last five years in the study area and all part of Ethiopia (Ethio Telecom, 2020). In Mari Mansa district above 75\% public servants use social media for different purposes. In public servant in office around the district are joining online social media webs based sites like Facebook, Messenger, Imo, Telegram, Twitter, Gmail, Instagram and TikTok. Social media invasion upon the public servants are now becoming the big challenge for sector and experts how to deal with it. Social media has negative affects office job performance and customer satisfaction. The most significant finding of this research is indicated that public servant impact on employers' performance and customer satisfaction. Based on the findings, employers who are involved in social media use has achieved lower job customer satisfaction on his/her job. They waste lot of time on using social media rather than doing office work and provide service to customers than those who have not social media account.

The result indicates social media users are victim of distraction during their service giving to customers and do different activity in office. Most of the public servants use social media during their work as a break and in their opinion social media does not distract them from doing their work or provide service to customer. Because social media is an application that can run in the background of internet devices so users do not need to engage with social media constantly.

The study result indicates there are many benefits and risks associated with using any social media. All of social media user public servants in district used a social media networking site on their phone. This increased the approachability and flexibility of being in touch. Smart features available on social media networks like reading 
RSS feeds, location tagging and status updates were popular uses of social network on mobile phone. The main problem of using social use in public servant life are they have low performance, they use social media when there is customer, spent more time on it rather than office work, addiction on it, resource wastage and extravagancy and face many other related problems from it. The result is supported by similar research conducted by (Andreas and Haenlein, 2010)

\subsubsection{The purposes why public servant use social media}

The first thing indicated by public servants is using social media is as a fashion and is globalization resulted from technology change. It is suitable technology result used primarily used to connect people. Social media are suitable devices for sharing ideas feeling, field visit and observations to others and experiences. It is the most feasible to comment, share and review organization and other individual messages in short time to more peoples. The result is supported by research conducted by (Barker, 2009). District public servants use social media for send and receive reports of their office to kebeles, zone, regions and other concerned body who required the reports of office activity, to see some important information's shared on fake accounts, to visit different media programs including Tvs, Radios, and others, to share field visit and observation, mailing, chatting, posting purposes, finding new friends, for communicating with the existing friends and find new information on required work of office.

Office dab of Agriculture and natural resource, Coffee tea and species and Animal and fisheries indicated they use social media to find important information on new disease and pest of crops and animals with their control method, to identify different diseases and pest symptoms, to identify cause of diseases and pest with management practices. They also indicated they receive different teaching material from federal subject matter specialist on how to produce, how to manage crops and animals and different related issues on social media. Generally idea collected from public servant on why they use social media are grouped as fashion and globalization, to send and receive message to friends, family and relatives, to send and receive reports, to share field visit and observation, to visit different media, to more than two purposes and to all purposes. There is no public servant in district as addiction.

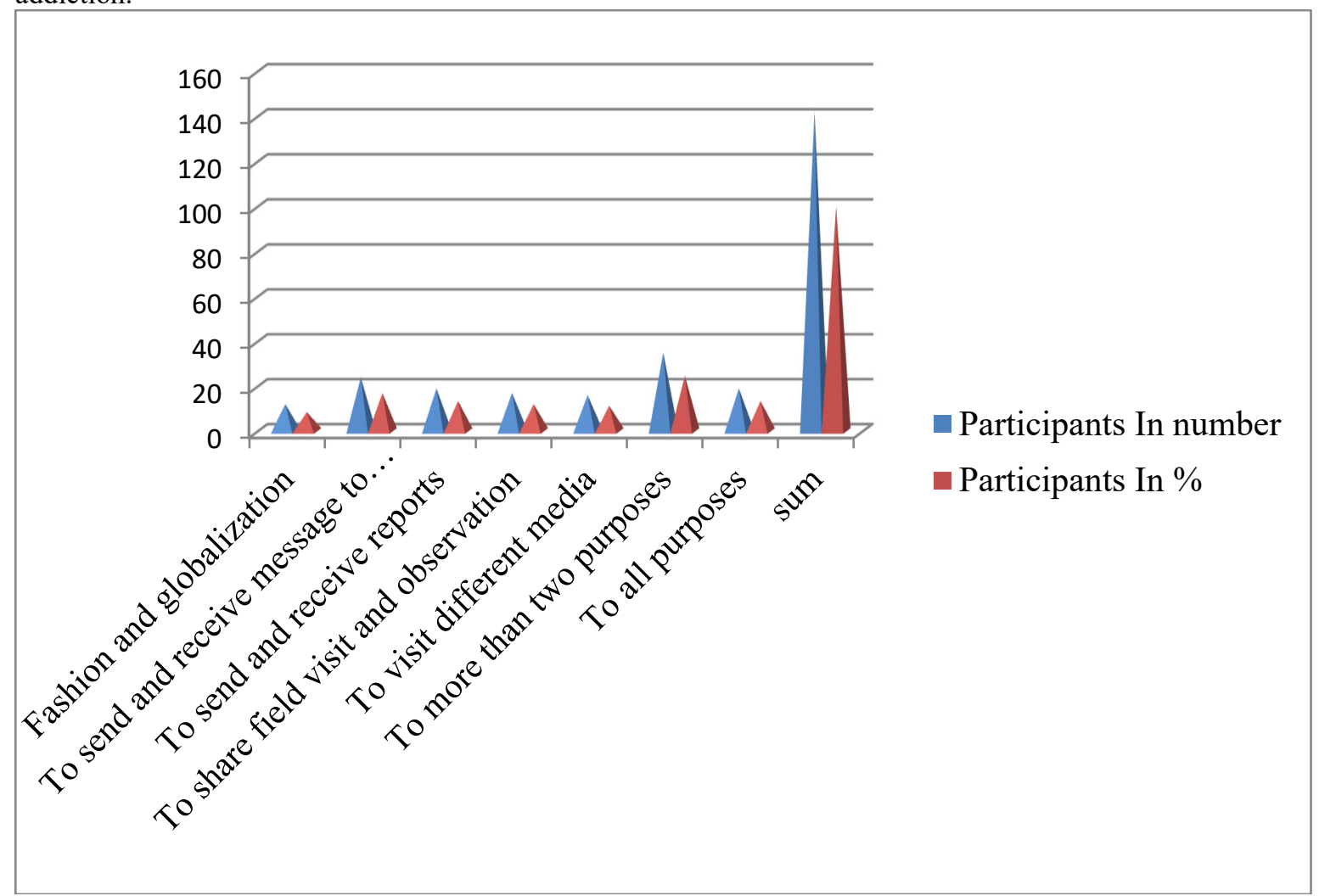

Figure 2: Reason why public servant use social media

Source: Own survey result 2019/2020

\subsubsection{Challenges and opportunities of social media}

\subsubsection{Challenges of social media}

The result revealed there are many challenges caused by using social media. The social media user public servants in district were bottlenecked with many challenges. These challenges are caused to the user by economical, social and technological constraints and result is supported by study result of (Sahem et al., 2012). 


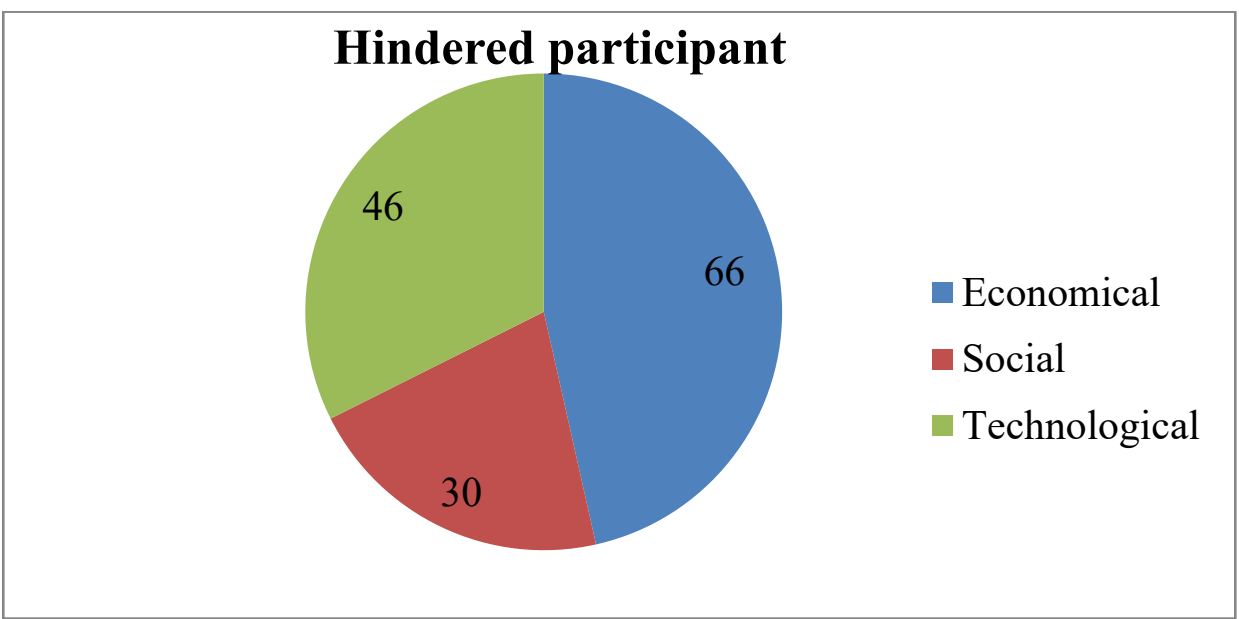

Figure 2: Constraints of social media

Source: Own survey result 2019/2020

i. Economical constraints

$\checkmark \quad$ Using social media require additional money rather than required to basic needs.

$\checkmark$ Employer with low income (salary) does not use social media because it charges high amount of money in hour.

$\checkmark \quad$ Many public servants defalcates high amount of money on social media this cause some problem on basic need fulfillments.

$\checkmark \quad$ Only smart phones owners use social media.

$\checkmark \quad$ The cost of smart phone is increasing from time to time.

$\checkmark$ Cost of mobile data is high

ii. Social constraints

$\checkmark$ Cost of smart phone is high

$\checkmark$ Some user post false information on fake account and this cause chasm between office member and other peoples without any evidence.

$\checkmark \quad$ Some user use social media message some ideas that are not expected with culture and belief. It makes communication easy to express idea in freely that face to face contact and make over confidence in false idea.

$\checkmark \quad$ It cause effect on the deterioration of social norms and ethics, psychological disorders like: antisocial behavior and aggressive tendencies.

$\checkmark$ Time spent on social reduce customer satisfaction

\section{iii. Technological constraints}

$\checkmark$ There is no opportunity to use social media in all types of phones only smart phone owners have opportunities to use social media.

$\checkmark \quad$ There is network coverage problem in some parts of the office.

$\checkmark \quad$ They use only mobile data only because of there is no access of WLAN and other opportunities in the district.

$\checkmark \quad$ There are no internet cafes in district.

$\checkmark$ Absences of WLAN and other opportunities in government office

\subsubsection{Opportunities of social media}

The study result revealed social media make the government and government services more accessible to citizens from one centralized place, helping to inform citizens by documenting valuable public information online, improving public access and awareness to a government of information. Social media make fastest means of communication between users and have other most important opportunities. The result is supported by similar research (Boyd, 2007).

$\checkmark \quad$ Easy to send and receive reports

$\checkmark \quad$ Easy to disseminate idea

$\checkmark \quad$ Reduce cost communication compared with direct call

$\checkmark$ Reduce time, money and wages wastages

$\checkmark \quad$ Feeling much more comfortable and through free when sharing opinions and thoughts

$\checkmark$ Easy way to get information on required idea

$\checkmark \quad$ Build knowledge 


\section{Recommendations and Conclusions}

Now a day social media is increasing way of communication to public servants in the district and Facebook play the lion share on social media. Based on the result revealed from this study, the public servants were aware of the social networking sites and they have no more access to them though social media and social media have negative effects on public servants, distracting them from their office services, taking most of their productive time and they also have benefits and can be used appropriately. Most common social media used by district public servants are platforms Facebook, Messengers, Imo, Twitter, Instagram, Telegram, Telegram, Telegram, Email and TikTok. Impairment of job performance and social media dependency are correlated by utilizing synchronous communication programs including internet sites and forums. There are challenges and opportunities associated with using social media. Social media user of public servant uses it also for mailing, reporting, sharing, chatting and posting purposes. The results of this study recommend that public servants and other stakeholders should come up with a template on how public servant can maximize the benefits of social media, that is government should incorporate rules and regulations on the use of the social media let alone phones in the office, and the management must be able to regularize the uses mobile data use work time.

Finally, it is very important undertake further research in public office social media use and how mobile internet and multitasking activities affects public servants job performance on large samples of public servants from different office in different level from kebeles to national level to get enough knowledge.

\section{References}

Ahn, M.J. (2010), "Adoption of e-communication applications in US municipalities: The role of political environment, bureaucratic structure and the nature of applications", in American Review of Public Administration, 41 (4), pp

Andreas M., Haenlein Michael (2010). "Users of the world, unite! The challenges and opportunities of social media". Business Horizons 53 (1). p. 61.

Asemah, E.S and Edegoh, L.O.N. (2012). Social media and insecurity in Nigeria: a critical appraisal. Being a paper presented at the $15^{\text {th }}$ National Conference of African Council for Communication Education, which took place at the conference Hall of Federal University of Technology, Minna, Nigeria.

Barker, V. (2009). Older adolescents' motivations for social network site use: The influence of gender, group identity, and collective self-esteem. Cyber Psychology and Behavior, 12, 209-213.

Błachnio, A., Przepiorka, A., Boruch, W., \& Bałakier, E. (2016). Selfpresentation styles, privacy, and loneliness as predictors of Facebook use in young people. Personality and Individual Differences, 94, $26-31$. https://doi.org/10.1016/j.paid.2015.12.051.

Boyd, D. 2007. Why youth (heart) social network sites: The role of networked publics in teenage social life. MacArthur Foundation Series on Digital Learning-Youth, Identity, and Digital Media Volume. Cambridge, MA: MIT Press. 1-26.

Dhir, A., \& Tsai, C. (2017). Understanding the relationship between intensity and gratifications of Facebook use among adolescents and young adults. Telematics and Informatics, 34, 350-364. https://doi org/10.1016/j.tele.2016.08.017.

Ethio Telecom. (2020). 2019/2020 The annual Statistics Reports of Mobile and Internet Usage of Ethiopia

Kietzmann, H. (2012). "Social media? Get serious! Understanding the functional building blocks of social media". Business Horizons 54: 241-251.

Lev-on, A. (2017). Telematics and informatics the third-person effect on Facebook: the significance of perceived proficiency. Telematics and Informatics, 34, 252-260. https://doi.org/10.1016/j.tele.2016.07. 002.

Mergel, I. (2013a), "A framework for interpreting social media interactions in the public sector", in Government Information Quarterly, 30(4), pp. 327-334.

Mesch, G. (2009). Parental mediation, online activities, and cyber bullying. Cyber Psychology and Behavior, 12 , 387-392.

Mesfin Z., Tolosa D. Hirko T and Gadise G. 2017. The Impacts of Social Media on Academic Achievement of Female Students at Jimma University.

Mickoleit, A. (2014), "Social Media Use by Governments: A Policy Primer to Discuss Trends, Identify Policy Opportunities and Guide Decision Makers", OECD Working Papers on Public Governance, No. 26, OECD Publishing. http://dx.doi.org/10.1787/5jxrcmghmk0s-en

Sahem. N, Osama. H, Samaher. F, Ruba O and Osama. R., (2012). Facebooks Impact on Users Social Life. Journal of American Science 2012; 8 (12). 